\title{
EL DESARROLLO DE LAS CUBIERTAS COLGANTES PESADAS
}

\author{
(PROGRESS MADE IN HEAVY HANGING ROOFS)
}

Juan José Santos Guerras, Arquitecto INITEC-ESPAÑA

\section{RESUMEN}

En este articulo se aporta el proceso, las últimas realizaciones y el estado de desarrollo al que han llegado las cubiertas colgantes pesadas. Desde los años 50, las estructuras de Frei Otto, de Fritz Leonhardt, las cubiertas circulares de Viera, Severud, SOM y de las Olimpiadas de Münich o Moscú, se explica la evolución de este sistema constructivo, con su influencia en los últimos puentes de banda tensada y las realizaciones en nuestro país de Fernández Casado, Páez, Fernández Villalta y Cobelas, presentando una documentación gráfica inédita en España.

\section{SUMMARY}

This article describes the progress, the latest models and the state of development attained by heavy hanging roofs. Since the 50's, the structures of Frei Otto, of Fritz Leonhardt, the circular roofing of Viera, Severud, SOM and the Olympic

Stadiums of Munich and Moscow all show the development of this construction system, and its influence on the latest suspension bridges and the work in our country of Fernández Casado, Páez, Fernández Villalta and Cobelas, presenting an unedited illustrated documentation in Spain.

\section{CUBIERTAS COLGANTES PESADAS}

Frente a las cubiertas colgantes ligeras - superficies anticlásticas, tipo hiperbólico - en las cuales mientras que una familia de cables cuelga, otra los tensa, creando un conjunto rígido a la deformación y permitiendo una cobertura muy liviana (por ejemplo en los edificios para la Olimpiada de Münich de 1972), las cubiertas colgantes pesadas son básicamente superficies sinclásticas de curvatura negativa con forma de catenaria que, para lograr la estabilidad frente a cargas puntuales 0 esfuerzos de succión del viento, necesitan la contribución de su peso propio.

Si bien desde los tiempos primitivos podemos encontrar ejemplos de cubiertas colgantes, no es hasta la década de los años 50 del presente siglo cuando van a experimentar un considerable desarrollo teórico y práctico apoyado en los avances técnicos alcanzados por la ingeniería en la construcción de puentes (1).

La Arena de Raleigh (Fig. 1) fijó el punto de partida. La brillante idea que dio origen a este edificio la tuvo el arquitecto Matthew Novicki en 1950. Entre dos arcos de hormigón inclinados colgaban los cables que soportarian la superficie de la cubierta. Novicki no había dibujado en sus croquis cuerdas tensoras y seguramente no se las imaginaría, aun cuando enlazara los dos puntos de cruce de los arcos con una línea que indi-

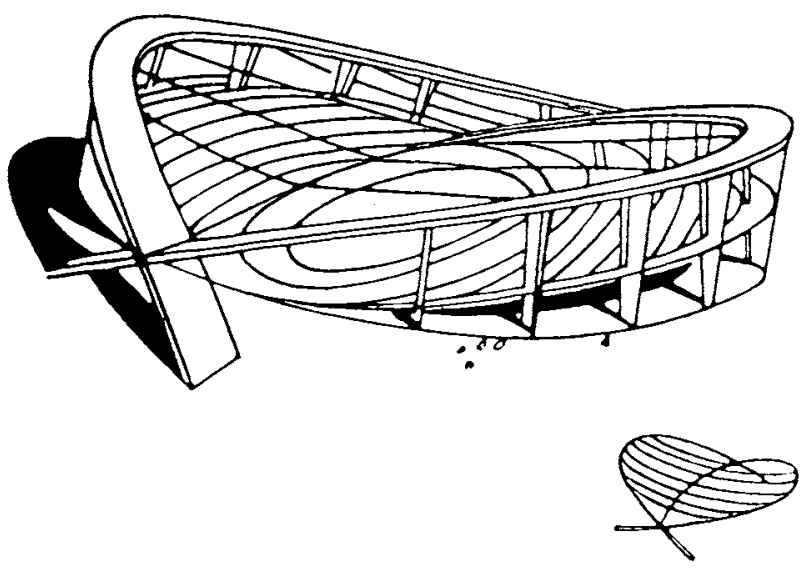

Fig. 1.-Croquis de la idea de Matthew Novicki para la Arena de Raleigh. 
caba la curvatura positiva en aquella dirección. Fue, sin embargo, el ingeniero neoyorquino Fred Severud (desgraciadamente Novicki habia muerto ese mismo año en un accidente aéreo) quien llevó a cabo esta idea, in. troduciendo una segunda familia de cables transversales que conseguiría el pretensado de la red, sobre la que se dispuso una cubierta de chapa perfilada.

\section{FREI OTTO}

Frei Otto - que venia trabajando en el diseño de cascarones de hormigón de gran luz por medio de modelos colgantes o funiculares que luego invertia, obteniendo así la forma estáticamente óptima para un determinado esquema de cargas - tuvo la oportunidad de ver la maqueta de la Arena en diciembre de 1950 cuando, en un viaje de estudios a Estados Unidos, visitaba el despacho de Severud. El arquitecto alemán constató, a la vista del modelo, las posibilidades que las estructuras colgantes ofrecian a la construcción de cubiertas y, a su regreso a Alemania, emprendió la tarea del estudio de éstas.

Si bien en un principio sólo fijó su atención en estructuras ligeras en forma de paraboloide hiperbólico como la Arena de Raleigh, enseguida, a raiz de un concurso para una pequeña sala de música en Berlín, diseñó una cubierta colgante unidireccional compuesta por cables suspendidos de los extremos de la sala y sobre los que se disponían perpendicularmente vigas de acero que rigidizaban la cubierta en el sentido transversal y permitian un sencillo cuajado a base de piezas prefabricadas de hormigón ligero (Fig. 2). Las vigas podrian ser sustituidas por placas de hormigón que apoyarian directamente sobre los cables (Fig. 3), o también por tablas de madera dispuestas en varias capas (Fig. 4), o directamente vertiendo sobre los cables, sobre los que se habria tendido previamente una malla de acero, hormigón ligero gunitado que podría posteriormente ser postensado evitando asi la aparición de fisuras (Fig. 5).

En el período que va desde 1951 a 1954 Frei Otto definió un gran número de tipologias constructivas que serian llevadas a cabo, en años posteriores, por otros arquitectos e ingenieros.

En 1954 publicó el libro "La Cubierta Colgante" (2), que alcanzaría una gran difusión y que representó el primer trabajo de investigación sistemática sobre esta faceta de la construcción, además de contener la primera recopilación de los ejemplos hasta entonces existentes. (c) Consejo Superior de Investigaciones Científicas

Licencia Creative Commons 3.0 España (by-nc)

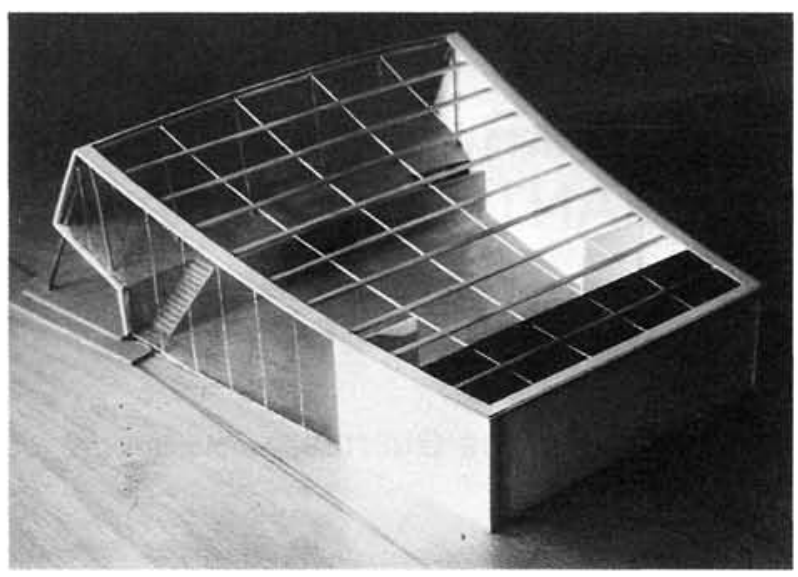

Fig. 2.-Maqueta de un aula del Instituto francés en Berlin. La cubierta está proyectada con un sistema de vigas y cables. La forma colgante resulta también muy adecuada para las necesidades acústicas de sa. las de conferencias y conciertos.

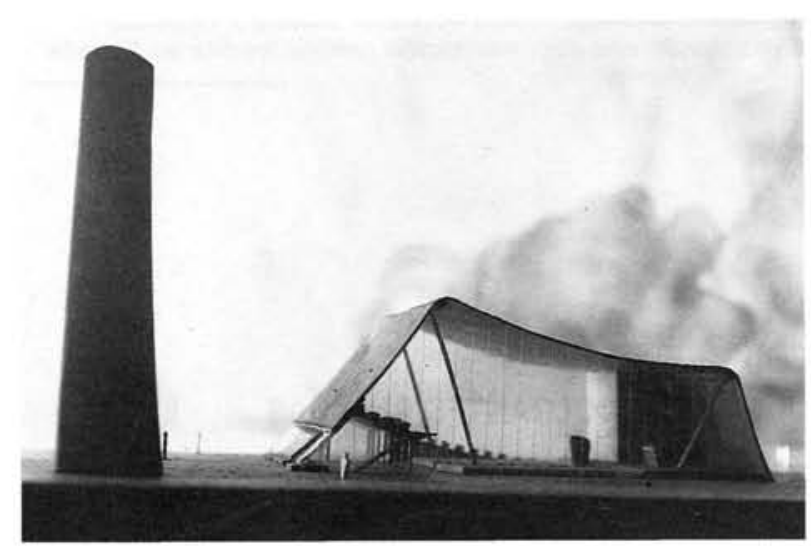

Fig. 4.-Maqueta del proyecto de una iglesia en Berlín. La cubierta admite distintas soluciones constructivas: hormigón gunitado, pie. zas prefabricadas, capas de tablas de madera.

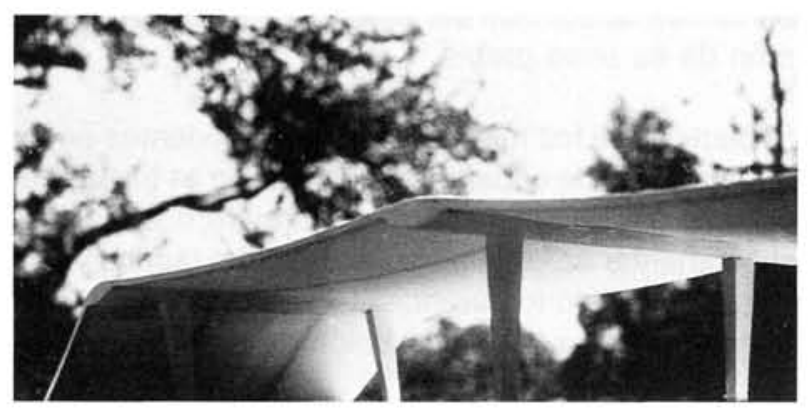

Fig. 5.-Frei Otto, recinto para exposiciones al aire libre en hormigón gunitado y postesado.

http://informesdelaconstruccion.revistas.csic.es 
NAVE A bASE DE PIEJAS PREFABRICADAS
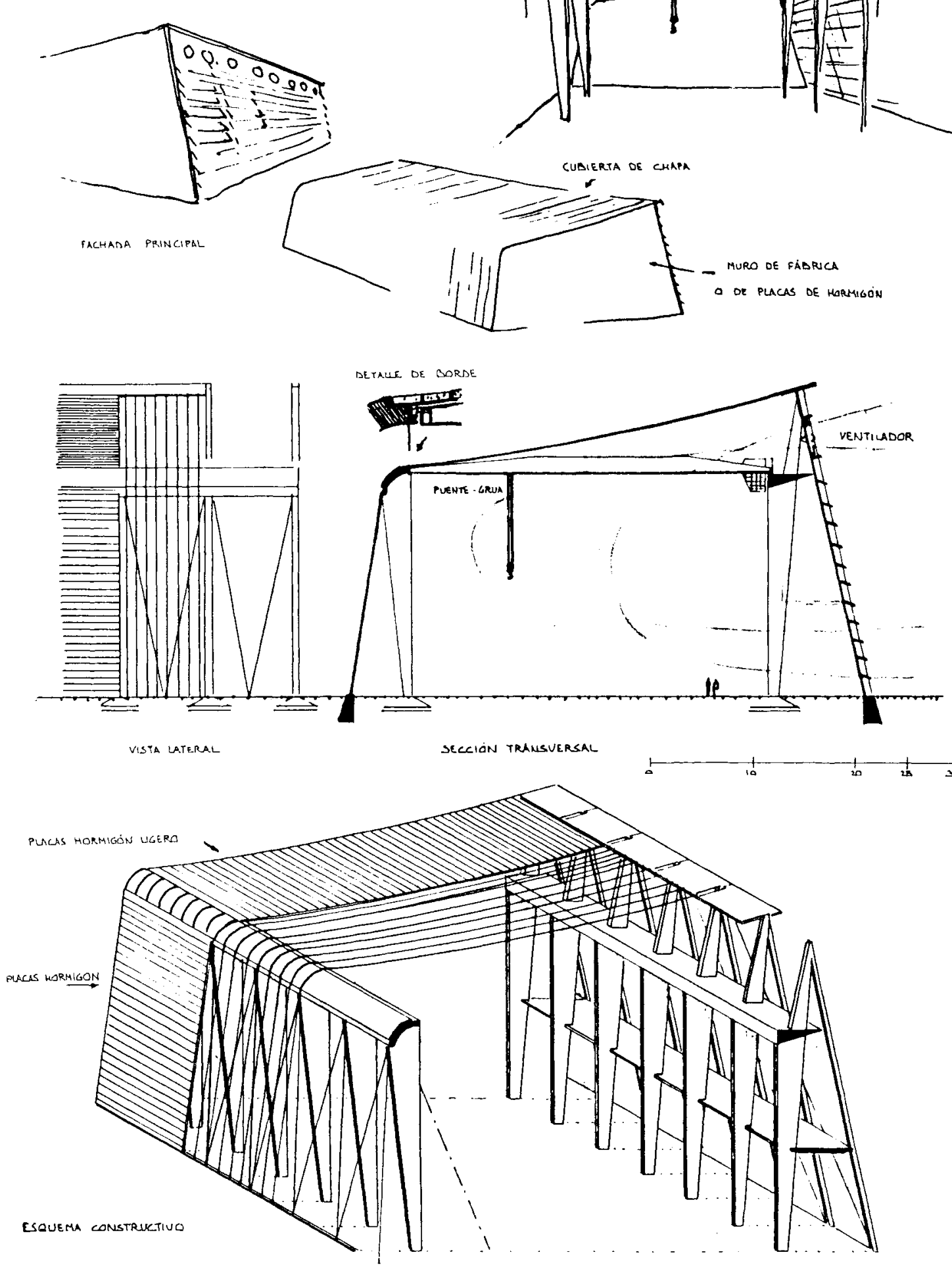

Fig. 3.-Diseño de Frei Otto para la sala de una central eléctrica. La cobertura está realizada a base de piezas prefabricadas de hormigón. 


\section{FRITZ LEONHARDT}

En 1954 se encontró Fritz Leonhardt por primera vez con Frei Otto; éste le presentó su libro recién publica. do "Cubiertas Colgantes". Las revolucionarias ideas del joven arquitecto pronto entusiasmarían a Leonhardt, quien, dotado de la mentalidad práctica de todo buen ingeniero, y basándose en sus grandes conocimientos técnicos de estructuras pretensadas, realizó obras tan interesantes como la piscina de Wuppertal en 1958, de $52 \mathrm{~m}$ de luz (Fig. 6). Desde dos vigas planas de hormigón armado que coronaban los graderíos laterales colgaba la estructura resistente compuesta por redondos de $24 \mathrm{~mm}$ de diámetro espaciados cada 20 ó $24 \mathrm{~cm}$, embebidos en una losa de hormigón ligero vertido in situ con un espesor medio de sólo $6 \mathrm{~cm}$. El conjunto fue postensado tanto en la dirección longitudinal como en la transversal, creando asi un efecto de lámina continua. O, en 1962, la piscina de Göppingen, de $30 \mathrm{~m}$ de luz, cuya construcción se realizó esta vez a base de piezas prefabricadas de hormigón ligero que apoyaban sobre los cables. Las juntas entre placas fueron hormigonadas y postensado el conjunto una vez fraguado el hormigón. El drenaje de la cubierta se consiguió en el primer ejemplo aumentando la flecha de las catenarias de los cables desde un extremo a otro, y en el segundo desde el centro hacia los extremos.

Fritz Leonhardt establece a través de estos ejemplos un claro sistema estructural que tendrá amplia repercusión, fundamentalmente en Alemania Federal, donde en la década de los 60 encontramos numerosos ejemplos de iglesias, piscinas y salas de exposiciones de estructura parecida a las descritas.

Pero va a ser en las realizaciones más modestas $-\sin$ postensar y que no necesitan importantes elementos de borde, los cuales en cierta forma enmascaran la ligereza inherente a este tipo de estructuras - donde va a alcanzar, a nuestro juicio, las soluciones más hermosas: como en la cubierta para una gasolinera en 1958, de hormigón ligero de sólo $4 \mathrm{~cm}$ de espesor, utilizando un encofrado perdido de chapa estirada (Figs. 7 y 8); o en un almacén al aire libre en 1961, también de $4 \mathrm{~cm}$ de hormigón ligero y un revoco interior de yeso de $1,5 \mathrm{~cm}$ (Fig. 9).

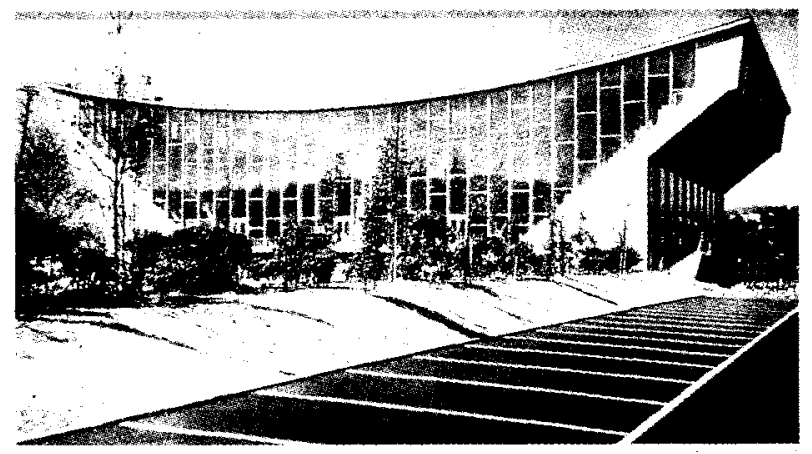

Fig. 6.-Fritz Leonhardt, piscina en Wuppertal (RFA). Vista de la fachada sur.

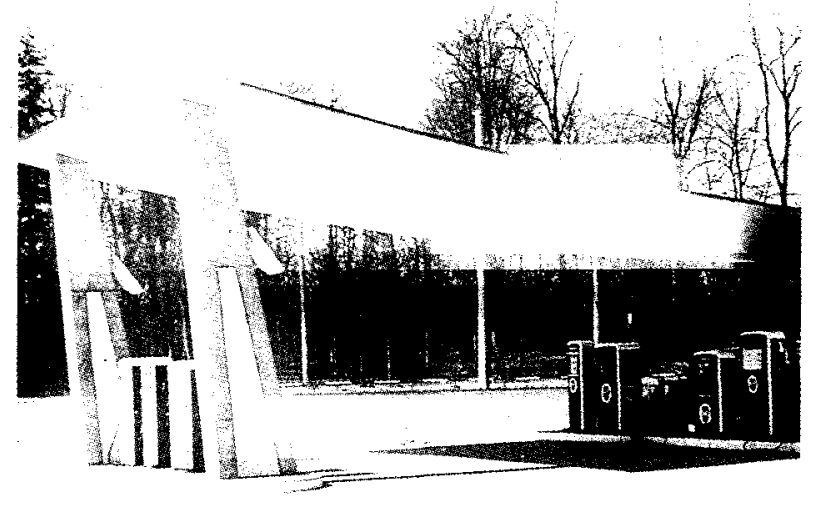

Fig. 7.-Fritz Leonhardt, cubierta colgante para una gasolinera, de $4 \mathrm{~cm}$ de hormigón ligero sin perfil de borde.

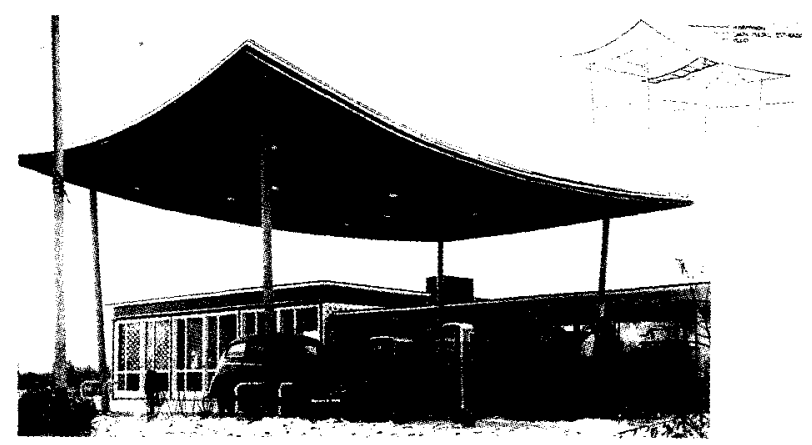

Fig. 8. - Cubierta con doble curvatura para una gasolinera, diseñada por el arquitecto H. Schwirtz siguiendo el mismo proceso constructi. vo que el utilizado por $F$. Leonhardt.

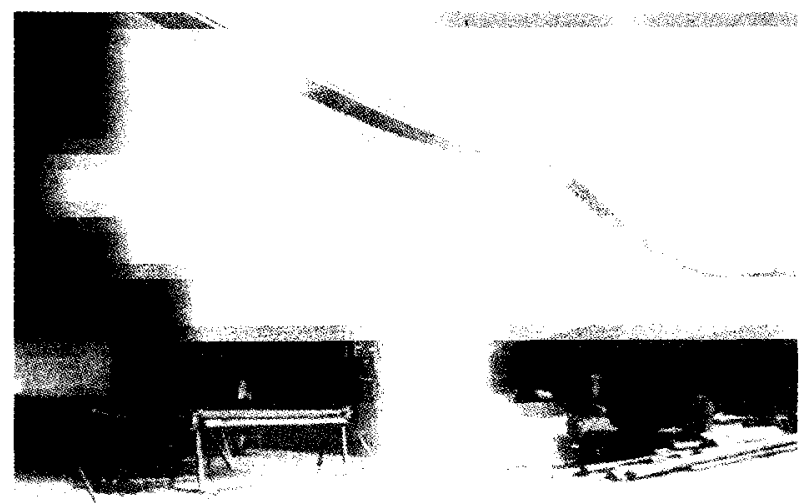

Fig. 9.-Tejado suspendido para un almacén al aire libre, con una luz de $10,5 \mathrm{~m}$ y tan sólo $4 \mathrm{~cm}$ de espesor. El armado principal está compuesto por redondos de $8 \mathrm{~mm} \varnothing$ cada $30 \mathrm{~cm}$.

http://informesdelaconstruccion.revistas.csic.es 


\section{CUBIERTAS CIRCULARES}

Las cubiertas colgantes circulares pesadas merecen un capítulo aparte en este artículo por su empleo tan extendido. En éstas, el elemento soportante tiende des. de un anillo exterior de compresión a otro interior de tracción. Básicamente son dos las variantes que podemos encontrar: en la primera, la cobertura se realiza en forma de membrana de chapa de acero que se rigidiza, bien colocando un recubrimiento superior de hormigón aislante proyectado o bien introduciendo una carga adicional (que bien pueden ser las instalaciones de calefacción y aire acondicionado) en el anillo central de tracción (Fig. 10); en la segunda variante, se lleva a cabo la cobertura por medio de una red radial de cables sobre los que se disponen piezas prefabricadas de hormigón ligero.

En 1957 el ingeniero uruguayo L. I. Viera realizó el Pabellón de Montevideo de $100 \mathrm{~m}$ de diámetro (Figs. 11 y 12), siendo el primero en introducir el postensado en este tipo de cubiertas. Sobre los redondos de acero, dispuestos radialmente, se fijaron placas de hormigón ligero pretensado. Una vez colocadas todas las piezas, se cargó la cubierta con ladrillos consiguiendo una deformación adicional de los cables. En ese momento se procedió a hormigonar las juntas y una vez fraguado el hormigón se descargó la cubierta retirando los ladrillos, quedando así toda ella pretensada y evitándo. se de esta forma la aparición de fisuras y el problema de succión del viento.

Las cubiertas colgantes circulares vienen siendo un sistema ampliamente utilizado en Norteamérica para la construcción de pabellones. Un buen ejemplo lo constituye, por lo atrevido y novedoso de su planteamiento, el Madison Square Garden de Nueva York (Figura 13) de 1968, en el que volvió a participar Fred Severud. Sobre la cubierta se dispusieron una serie de locales que albergaban las instalaciones a la vez que aportaban peso y simplificaban el desagüe.

De interés es también el Coliseum de Oakland, California (Fig. 14), de $128 \mathrm{~m}$ de diámetro, en el que sobre cada cable apoyaba una costilla compuesta por piezas prefabricadas de hormigón pretensado e interconectadas por anillos concéntricos estableciendo un sistema muy rígido frente a las sobrecargas.

(c) Consejo Superior de Investigaciones Científicas

Licencia Creative Commons 3.0 España (by-nc)
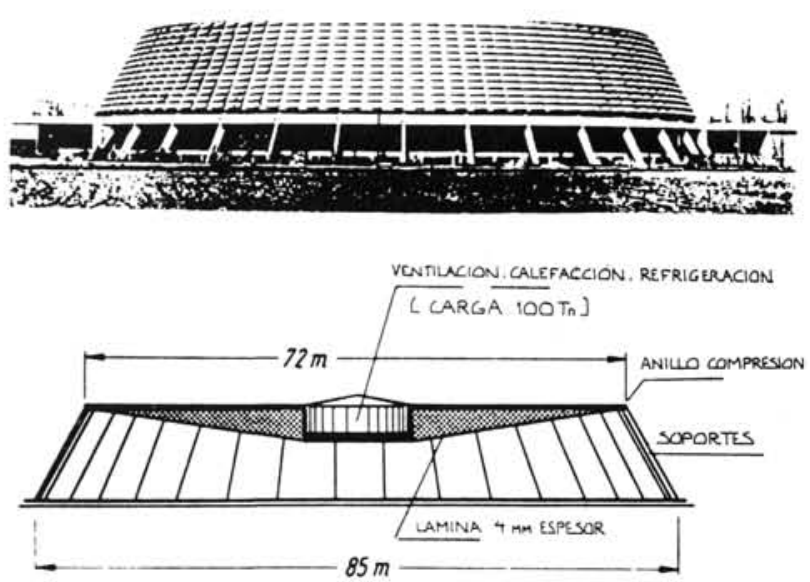

Fig. 10.-Pabellón de Baloncesto para los Juegos Olímpicos de 1972 en Münich.

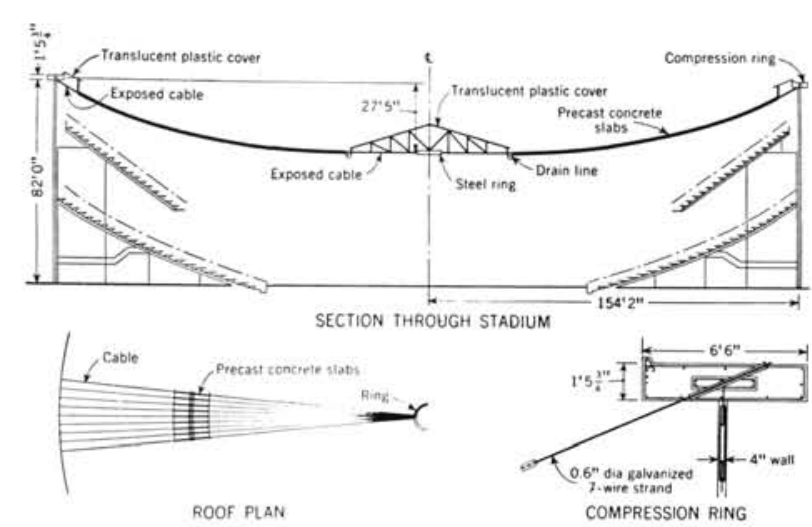

Fig. 11.-Pabellón de Montevideo, con una capacidad de 20.000 es pectadores, obra del ingeniero L. I. Viera.

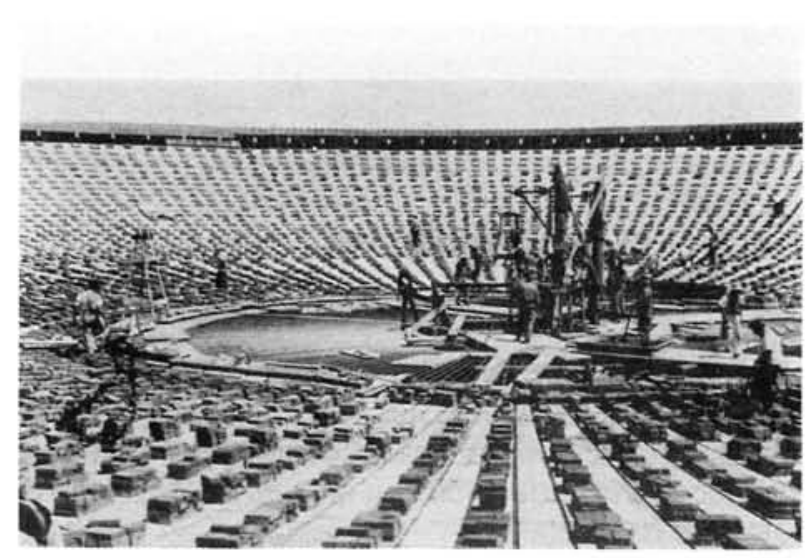

Fig. 12.-Vista de la cubierta del Pabellón de Montevideo con la so. brecarga de ladrillos.

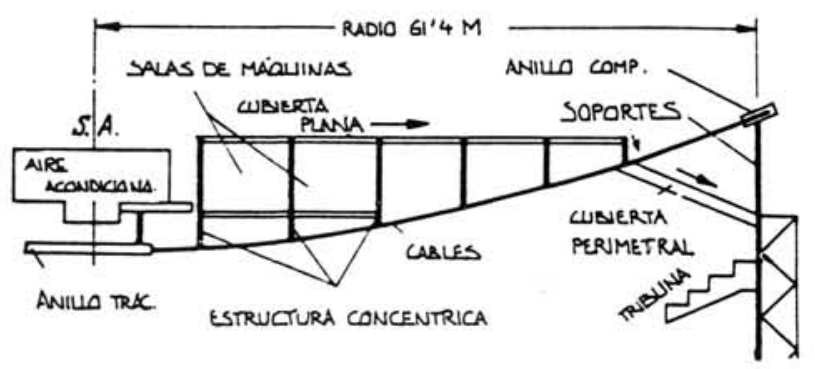

Fig. 13.-Sección de la cubierta del Madison Square Garden de Nue. va York, ingeniero F. Severud.

http://informesdelaconstruccion.revistas.csic.es 
Pero es en los.paises del bloque socialista donde estas estructuras, de fácil montaje y gran economicidad, han alcanzado la mayor repercusión, manteniéndose un continuo esfuerzo investigador que viene produciendo interesantes resultados. Decenas de soluciones, ya sea para garajes, pabellones o almacenes, podemos contar en la DDR, Checoslovaquia o la URSS. La experiencia acumulada en este campo permitió la construcción del Pabellón de Deportes de la Olimpiada de Moscú de 1980 (Fig. 15), de planta elíptica de $224 \mathrm{~m}$ por $183 \mathrm{~m}$ y capaz de albergar 45.000 espectadores - la sala más grande de Europa - con una membrana de chapa de acero de $5 \mathrm{~mm}$ de espesor rigidizada por un sistema de nervios radiales compuestos por cerchas.

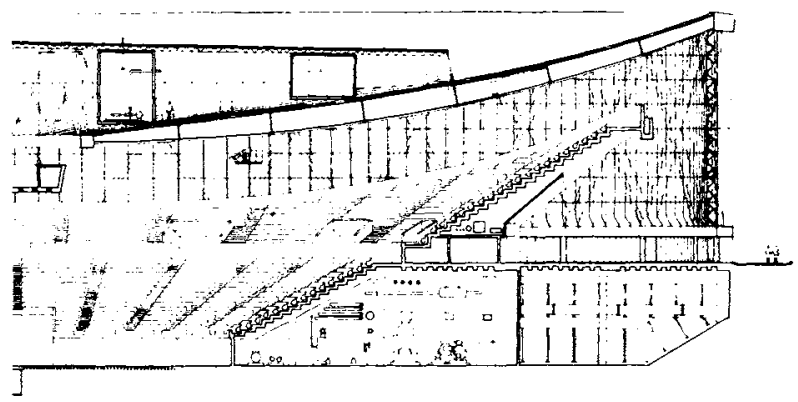

Fig. 14. - El Coliseum de Oakland con un aforo de 15.000 personas es obra de los arquitectos Skidmore, Owings and Merril.

\section{EVOLUCIÓN DE LAS CUBIERTAS COLGANTES PESADAS}

Los trabajos de Frei Otto tuvieron una amplia repercusión entre los ambientes arquitectónicos de los años 50 , época en la que las ideas organicistas imperantes encajaban a la perfección con la pureza estructural de este tipo de cubiertas.
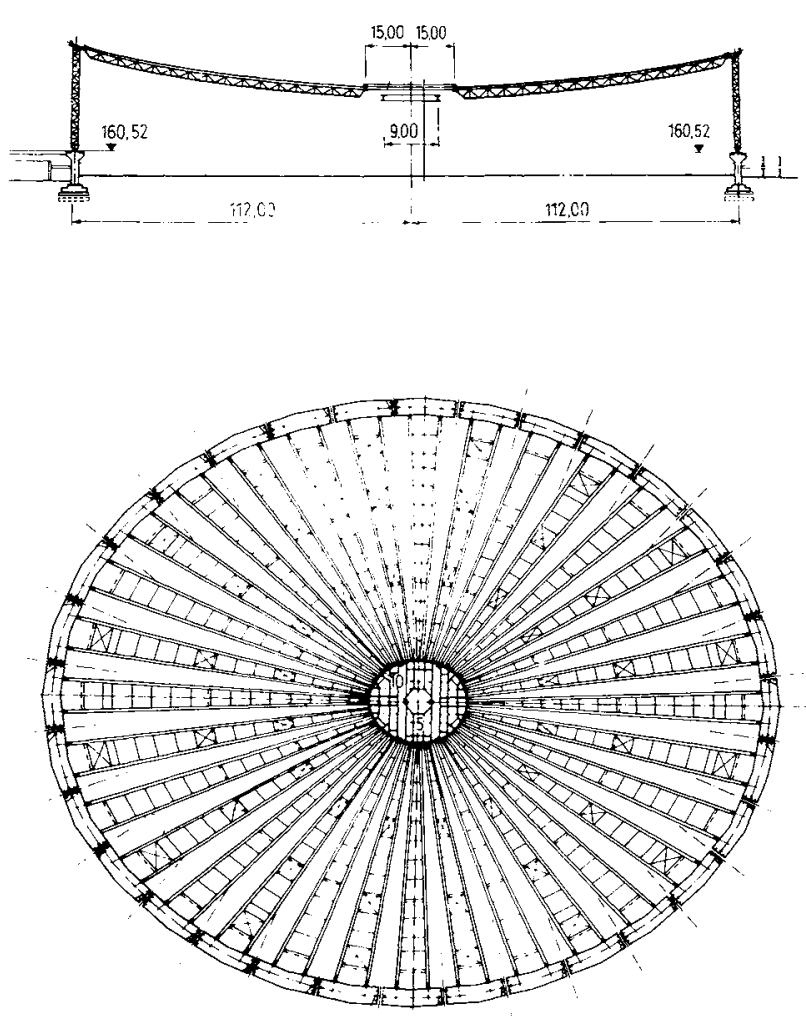

Fig. 15. - Pabellón de Deportes de los Juegos Olimpicos de 1980 en Moscú.

En 1952 Alvar Aalto, que seguramente ya conocia algún escrito de Frei Otto a través de la revista "Bauwelt", presentó para el concurso del Pabellón de Deportes de Viena una cubierta colgante de $120 \mathrm{~m}$ de luz (Fig. 16), que aseguró con unos vientos interiores, ya que su peso propio no era el suficiente en los extremos para hacer frente a las resacas producidas por el viento. Aalto en este edificio, dispuesto en planta en forma de abanico y con grandes fachadas inclinadas, consiguió sacar un gran partido a las posibilidades plásticas de estas cubiertas.

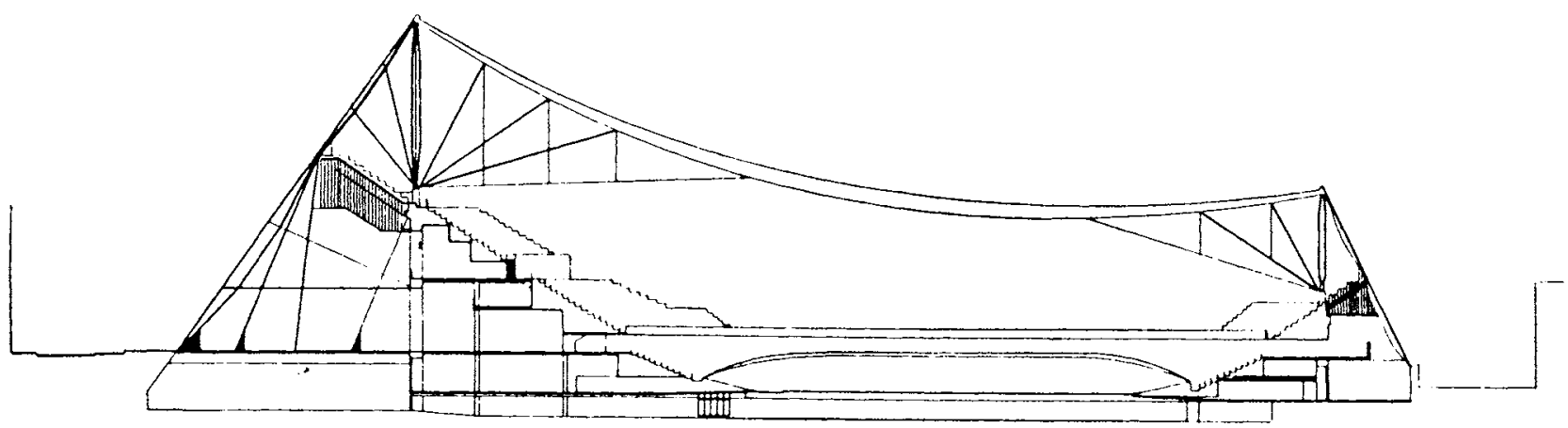

Fig. 16.-Sección de la Sala de Deportes de Viena de Alvar Aalto. Es una lástima que el proyecto, aun cuando ganase el primer premio, no se llegara a realizar. 


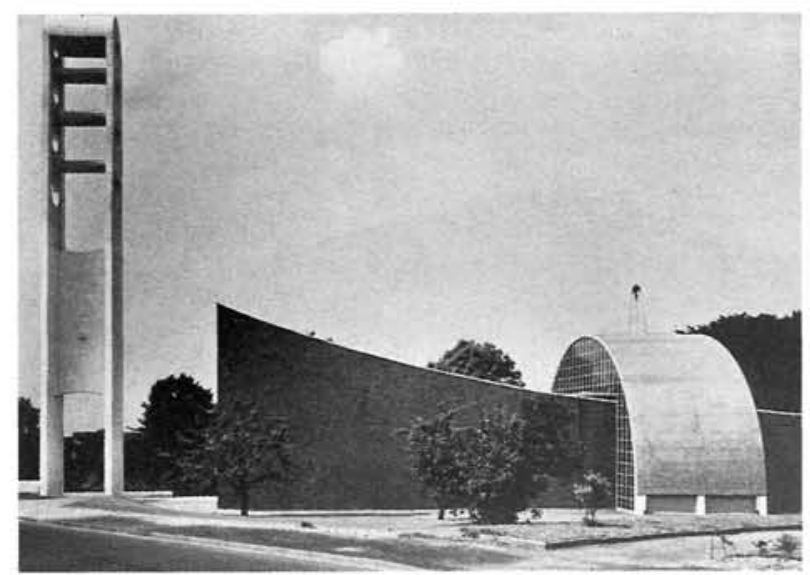

Fig. 17.-Vista lateral de la iglesia de San Pablo en Velbert (RFA), construida por Gottfried Böhm en 1954.

Por otra parte Gottfried Böhm (3) construyó, a mediados de los años 50, en el pueblo germano-occidental de Velbert la iglesia de San Pablo (Fig. 17), con una cubierta a base de cables de acero que colgaban de vigas en los extremos y sobre los que se apoyaba una fina chapa de metal estirada que servia como soporte de recepción del enlucido del techo, a la vez que actuaba como encofrado perdido de una lámina de hormigón ligero vertido in situ de $6 \mathrm{~cm}$ de espesor, la cual aportaba el peso y el aislamiento necesarios. La cubierta iba protegida al exterior por una manta asfáltica im. permeabilizante. Como ya hemos visto, este procedimiento también lo utilizó de forma similar Fritz Leonhardt.

Es en Estados Unidos donde encontramos, en 1956, la que constituye la primera cubierta colgante de plancha de acero construida a partir de la difusión de las nuevas teorias. Se trata del gimnasio para la Notre Dame High School en Niles, Illinois (Fig. 18). Una cubierta de $50 \mathrm{~m}$ de luz compuesta a base de planchas de $8 \mathrm{~m}$ de largo por 2,5 $\mathrm{m}$ de ancho y $6 \mathrm{~mm}$ de espesor, que llegaban a los $9 \mathrm{~mm}$ en los extremos, donde las solicitaciones eran mayores. Dichas planchas iban soldadas unas a otras formando una membrana continua sobre la que se verterian $7,5 \mathrm{~cm}$ de hormigón de vermiculita, que actuaba como ignifugo y aislante, a la vez que aportaba el peso necesario. Los movimientos de dilatación eran absorbidos por una junta de neopreno dispuesta en los muros laterales.

No fue hasta finales de los años 50 cuando aparecieron los primeros ejemplos que hicieron uso del hormigón pretensado. A los trabajos ya mencionados de Viera con el Pabellón de Montevideo y Leonhardt con la piscina de Wuppertal, debemos añadir los del ingeniero alemán F. Vaessen, quien en 1958 construyó en Dortmund un Pabellón de Exposiciones con una cubierta colgante de $80 \mathrm{~m}$ de luz (Figs. 19 y 20, pág. siguiente). Aquí los cables discurrian a través de nervios prefabricados de hormigón de $22 \mathrm{~cm}$ de ancho y $2 \mathrm{~m}$ de largo, (c) Consejo Superior de Investigaciones Científicas Licencia Creative Commons 3.0 España (by-nc)

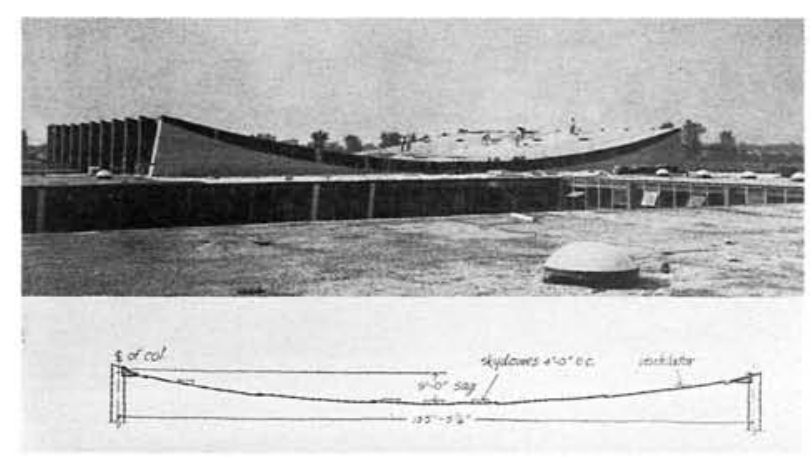

Fig. 18.-Gimnasio para la Notre Dame High School, Illinois. La cubierta se soldó y montó en sólo tres dias.

dispuestos cada 1,25 m sobre los que se colocaron unas placas prefabricadas de hormigón ligero de $5 \mathrm{~cm}$ de espesor, para posteriormente hormigonarse las juntas y postesarse el conjunto (Fig. 21).

De los tres ejemplos es el de Viera el único que no necesitó andamiaje de encofrado, elemento que, de hacerse necesario, encarecia enormemente este tipo de soluciones, por lo que en realizaciones posteriores se tendería a eliminar.

En la Exposición Mundial de Bruselas de 1958 una gran parte de los Pabellones eran cubiertas colgantes, aunque desgraciadamente no todas realizadas con la lógica constructiva que hubiera sido de desear. Debemos destacar, no obstante, el Pabellón Europeo (Fig. 22). Los cables cuelgan aqui básicamente de sólo dos pilares, venciendo una luz de $89 \mathrm{~m}$ y recurriendo para ello a vigas en celosía capaces de trabajar también a compresión. Una solución original a la vez que elegante.

A raiz de la Exposición de 1958, los arquitectos tenderian a valorar este tipo de cubiertas no por sus características estructurales, sino por su capacidad expresiva. Asi en 1963 E. Saarinen plantearia junto con F. Severud la terminal de pasajeros del aeropuerto de Washington. En el 64 las cubiertas de Kenzo Tange para la Olimpiada de Tokio atraerían el interés mundial. En el 65 Le Corbusier construiria una cubierta colgante para el albergue juvenil de Firmini.

Pero es a partir de la década de los 70 cuando los ejemplos se suceden con una mayor impronta formal, no produciéndose avances estructurales - salvo los ya mencionados de las cubiertas circulares - que podamos considerar de interés para este artículo.

Ha de ser, sin embargo, en el diseño de puentes, disciplina sin duda más alejada de criterios ornamentalistas, donde esta faceta de la construcción está alcanzando los resultados más notables.

http://informesdelaconstruccion.revistas.csic.es 


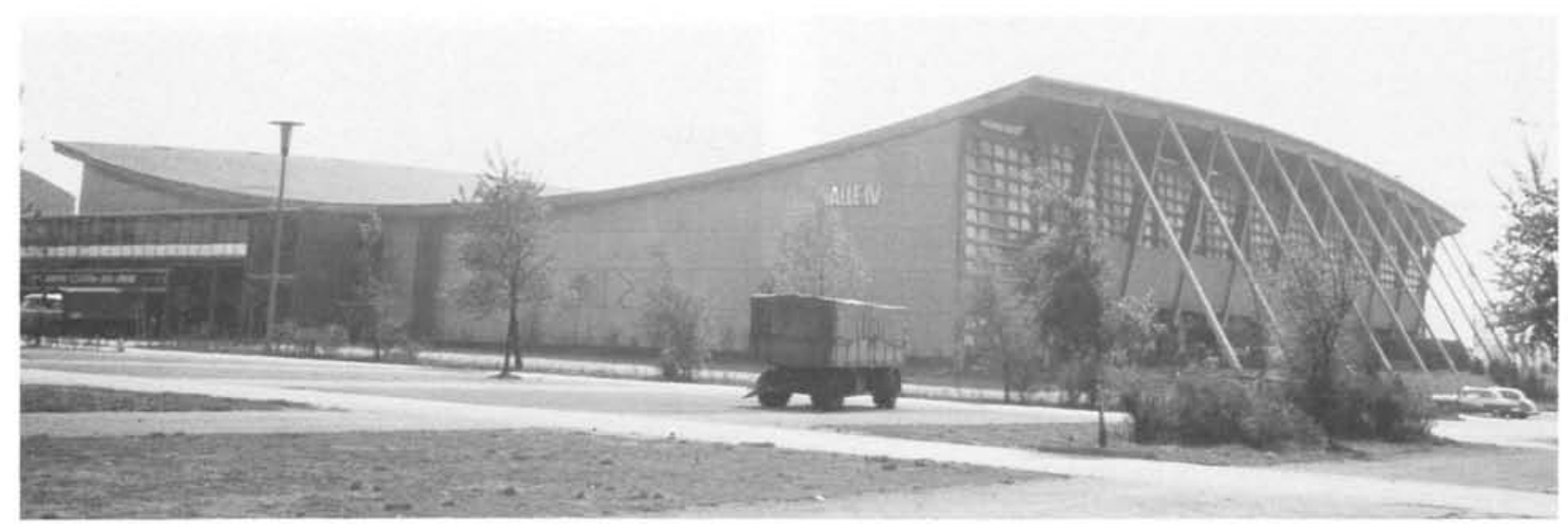

Fig. 19.-Pabellón de exposiciones de la Westfallenhalle en Dortmund (RFA), del ingeniero Franz Vaessen.

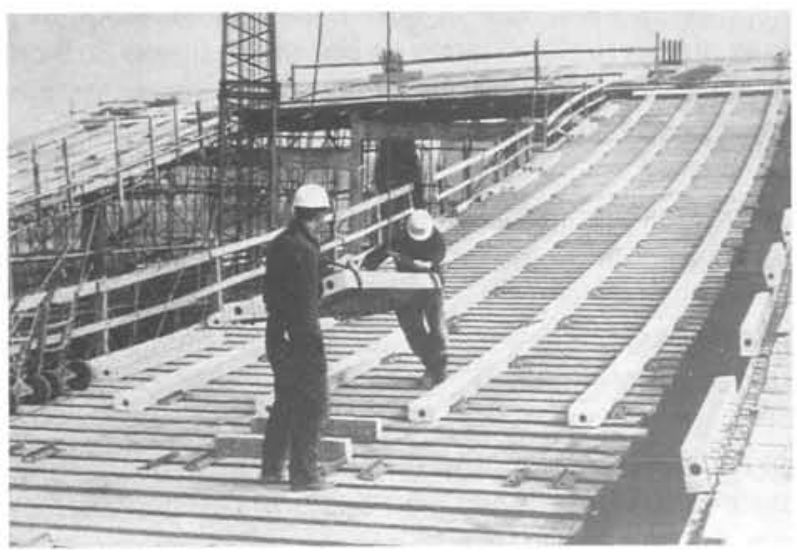

Fig. 20.-Aspecto de la cubierta durante su construcción.

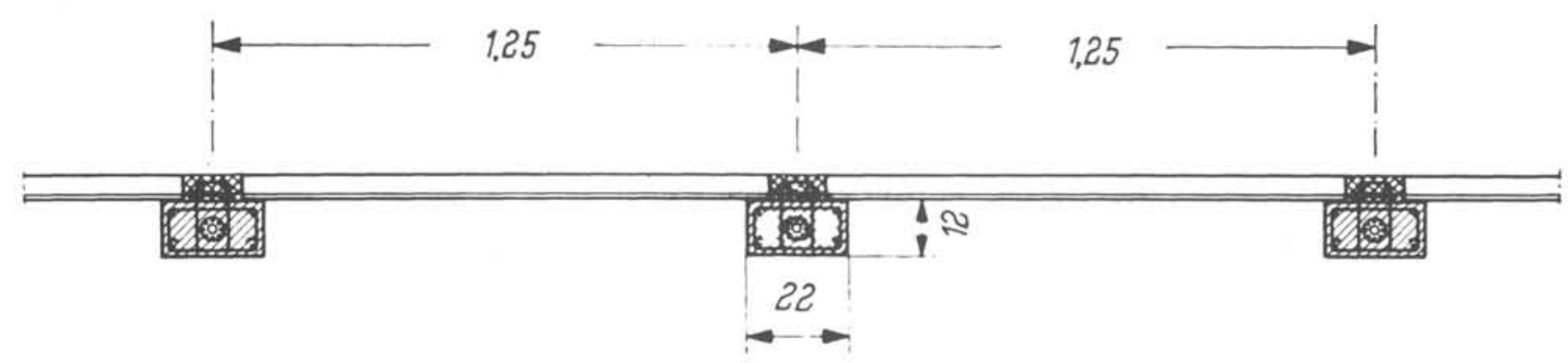

Fig. 21.-Sección perpendicular a la dirección de cuelgue.

Fig. 22. - El Pabellón Europeo para la Exposición Mundial de Bruselas de 1958 durante su construcción.

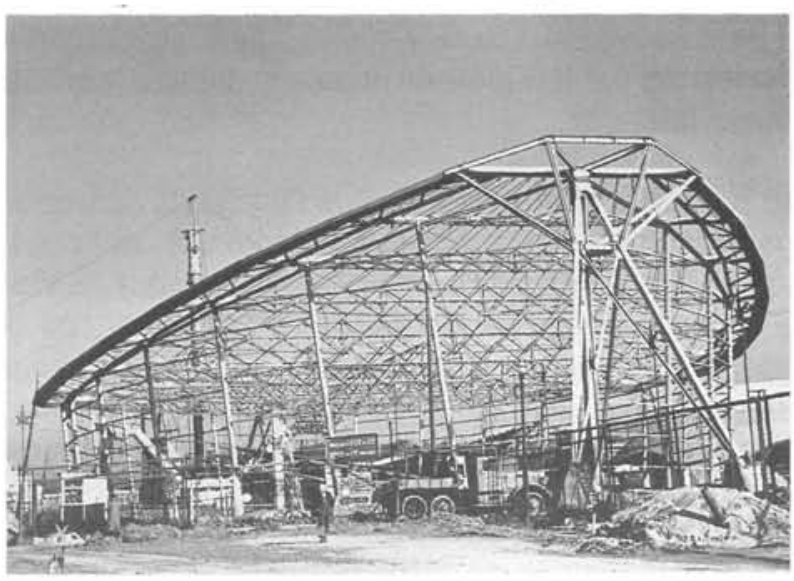

http://informesdelaconstruccion.revistas.csic.es 


\section{PUENTES DE BANDA TENSADA}

Estos, que constituyen el planteamiento más novedoso en la construcción actual de puentes, se caracterizan por contener en un solo elemento la viga de rigidización, el tablero y los cables portantes de los puentes colgantes habituales.

Debido a las exigencias del tráfico viario, la banda tensada requerirá una menor flecha de la catenaria que la vista para las cubiertas de edificios. Esta flecha se fija para el tráfico rodado en 1/100 de la luz, pudiendo ser algo mayor en pasarelas de peatones. Esto traerá consigo mayores esfuerzos de tracción en los cables, asi como importantes dispositivos de anclaje en el terreno. Por lo demás, estas esbeltas y elegantes construcciones presentan un carácter sumamente ventajoso, ya que son de fácil montaje y no necesitan accesorios de andamiaje. Además no precisan, al contrario que los puentes colgantes y atirantados, de la disposición de grandes pilones que sobresalgan en el paisaje. Pueden ser realizados con hormigón continuo 0 a base de piezas prefabricadas, suponiendo el empleo de áridos Iigeros un considerable ahorro de acero.

Los cambios de temperatura y carga producen el alargamiento o acortamiento de la banda, por lo que se dispone una pavimentación elástica, normalmente reali- zada a base de hormigones de resinas epoxi, que funciona también como impermeabilizante. Los fuertes momentos flectores que aparecen en los extremos se consiguen disminuir notablemente mediante la disposición de apoyos especiales de repercusión. Objeto de especial estudio es el comportamiento frente a las vibraciones, ya que se trata de estructuras de frecuencia natural muy baja.

Como en las cubiertas colgantes de hormigón, en las bandas tensadas siempre es aspirable una pequeña postensión que da rigidez a la estructura a la vez que disminuye la anchura de las grietas capilares.

La expresión "banda tensada" fue acuñada por el ingeniero alemán U. Finsterwalder quien planteó, en 1958, en el concurso para el puente del Bósforo, una solución de este tipo con tres vanos de aproximadamente $400 \mathrm{~m}$ cada uno ( $190 \mathrm{~m}$ eran propiamente cubierta colgante y el resto ménsulas que partían de los pilones). Tres años más tarde presentó una solución muy similar para el puente del Zoo de Colonia sobre el Rin (Fig. 23), con una luz principal de $294 \mathrm{~m}$ (163 m banda tensada) y sólo un espesor de placa de $24 \mathrm{~cm}$. Ambos ejemplos, sometidos a tracciones que alcanzaban las $75.000 \mathrm{t}$, hubieran necesitado, de haberse realizado, una gran cantidad de acero, del orden de $300 \mathrm{~kg} / \mathrm{m}^{2}$, y unos importantes elementos de anclaje en el terreno.

El primero en construir un puente de estas caracteristicas es el magnífico ingeniero uruguayo I. L. Viera (Fig. 24), autor como ya vimos del Pabellón de Montevideo. El puente, el único de los realizados hasta ahora que admite la circulación rodada, cuenta, sin duda para reducir las grandes tensiones producidas, con una flecha de catenaria relativamente grande, con lo cual su paso sólo es posible a velocidades moderadas (4).

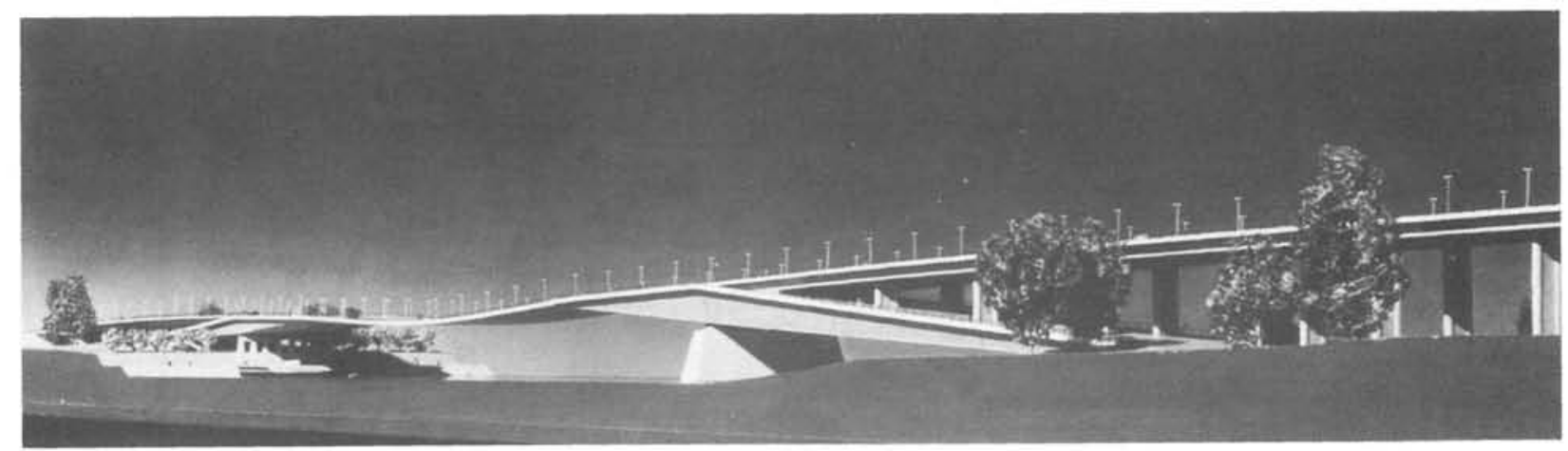

Fig. 23.-Proyecto para puente sobre el Rin en Colonia diseñado por U. Finsterwalder en 1961.

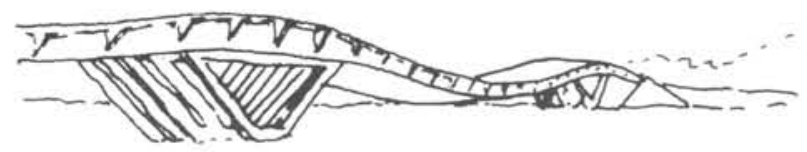

Fig. 24.-Puente sobre la Barra Maldonado (Uruguay). 


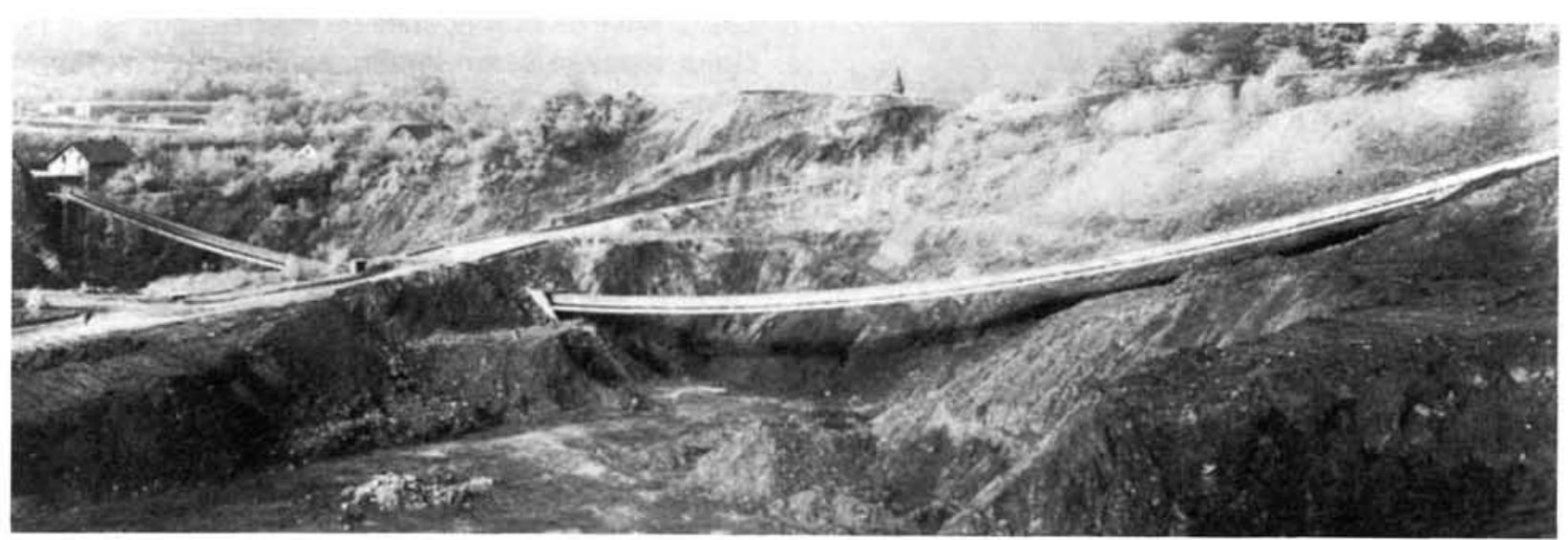

Fig. 25.-Belleza y sencillez van parejas en esta cinta transportadora para la fábrica de cemento Holderbank.

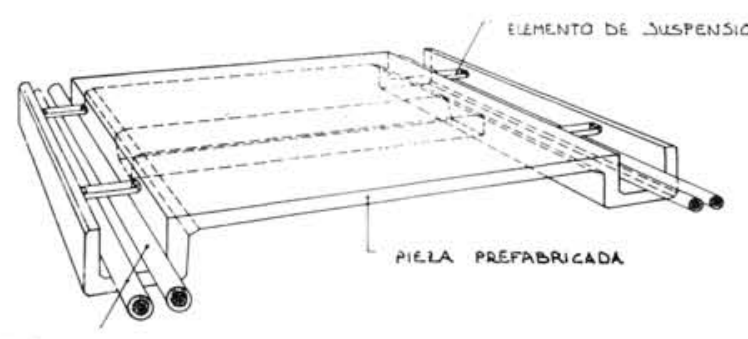

cades de Pastesado

Fig. 26.-Placa prefabricada de la cinta transportadora.

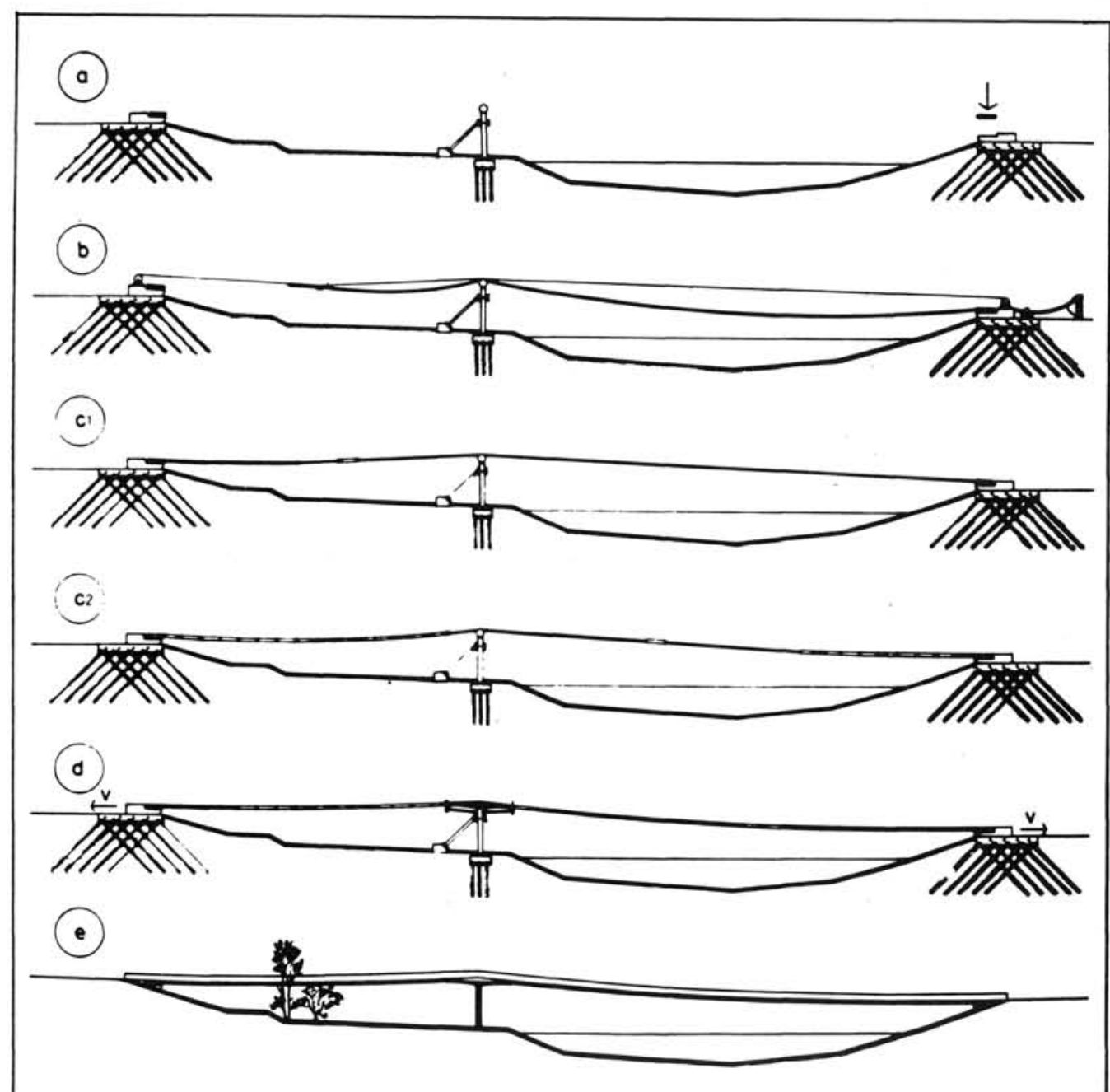

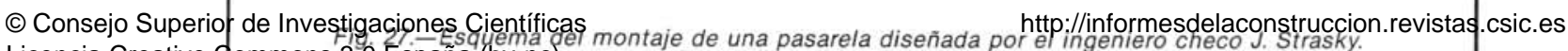
Licencia Creative Commons 3.0 España (by-nc) 
Para la cinta transportadora de una fábrica de cemento en Wildegg (Figs. 25 y 26), localidad cercana a Zürich, la empresa Züblin en 1964 diseñó una estructura de $216 \mathrm{~m}$ de luz compuesta a base de piezas prefabricadas apoyadas sobre cuatro cables suspendidos que aguantaban cada uno una tracción de 270 t.

Las juntas entre las piezas se hormigonaron in situ postensándose el conjunto.
El carácter rocoso del terreno permitió realizar el anclaje de manera muy económica.

Un campo idóneo de aplicación de la banda tensada lo constituyen las pasarelas de peatones. Muchos son los ejemplos que podemos contar en los últimos veinte años. Así desde 1980 y también a base de piezas prefabricadas, el ingeniero checoslovaco J. Strasky las viene realizando con notable éxito y luces de hasta $120 \mathrm{~m}$ (Figs. 27 a 29).

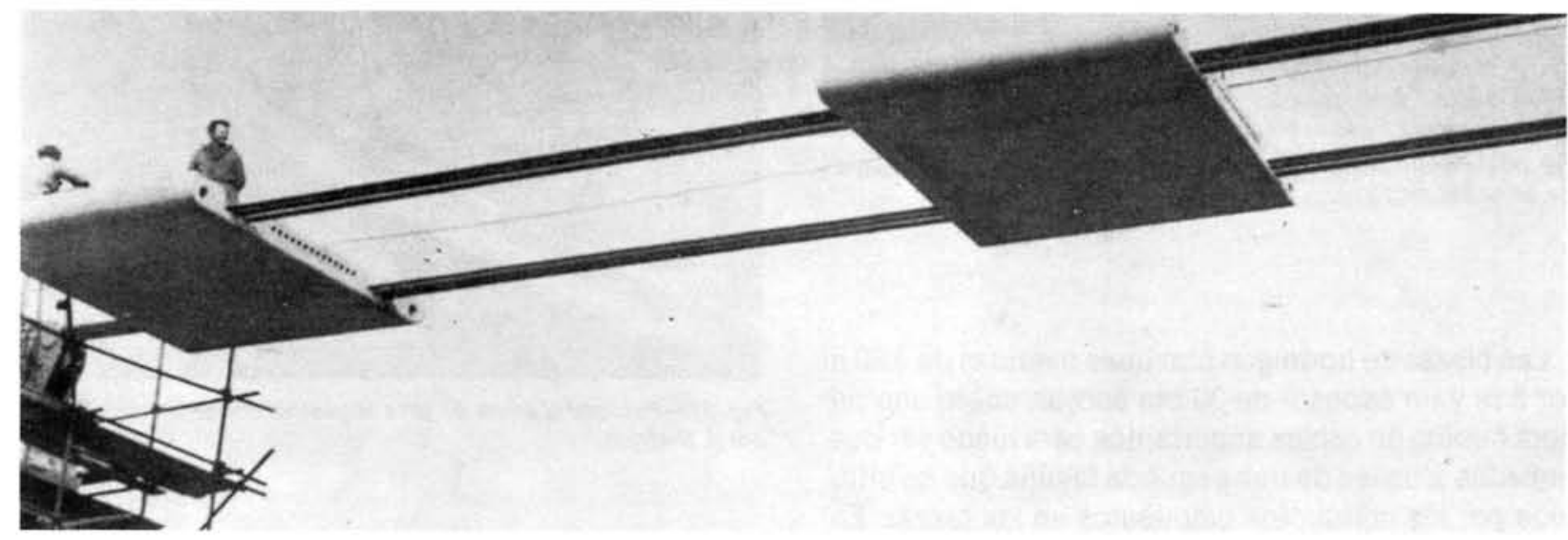

Fig. 28.-J. Strasky. Montaje de una de las piezas prefabricadas sobre los cables soportantes.

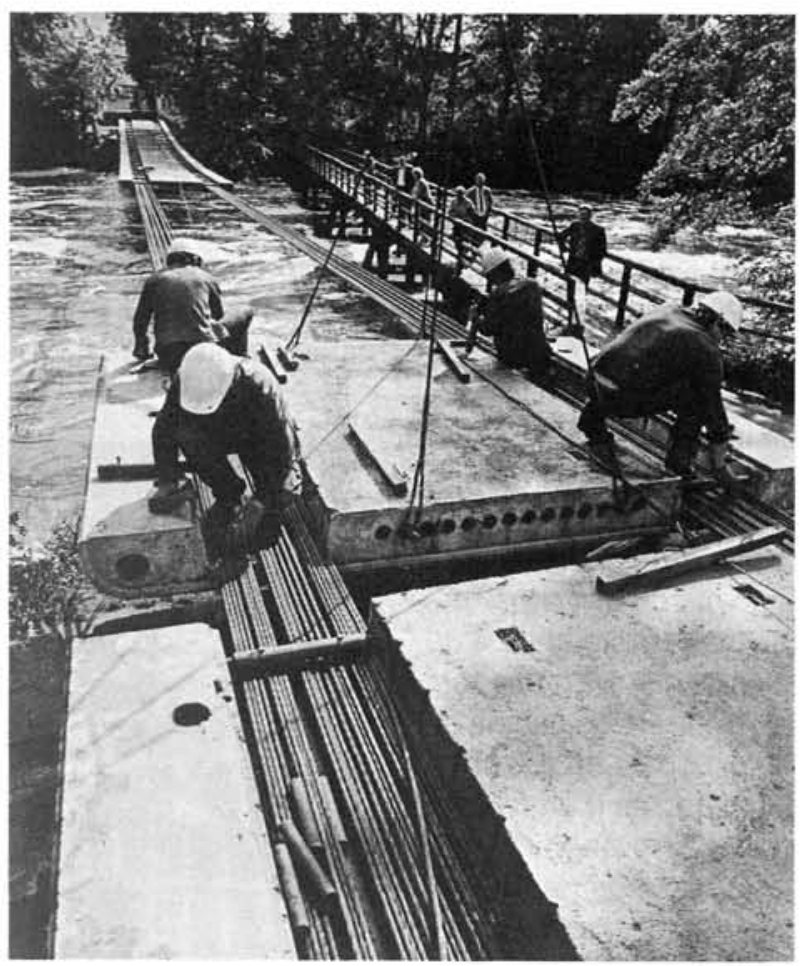

Fig. 29.-Momento del ensamblaje de dos piezas del tablero. Los cables del postensado se introducirán posteriormente a través de los conductos centrales. 


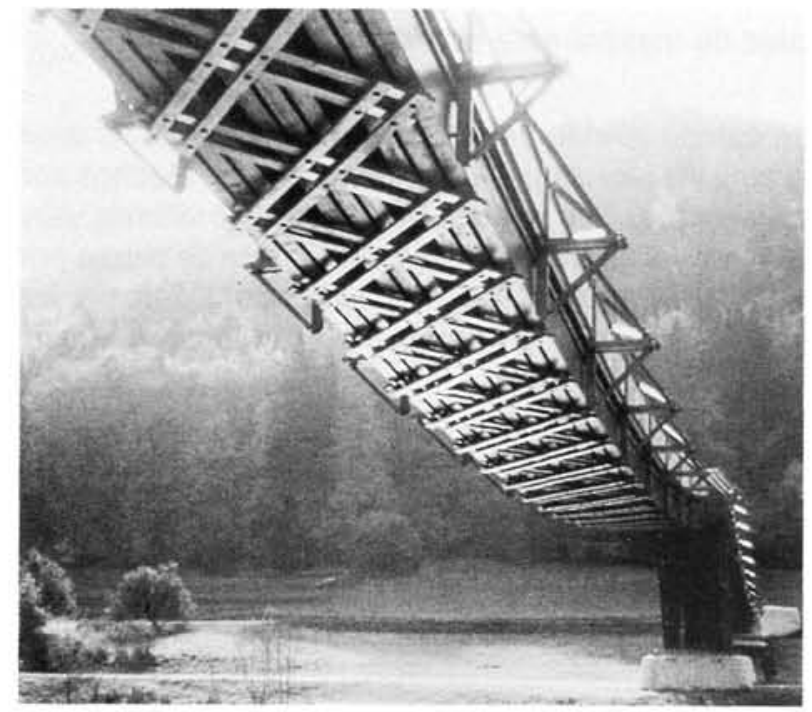

Fig. 30.-Pasarela sobre el Altmühltal en Essing (RFA) de 4 vanos y luz principal de $73 \mathrm{~m}$.

Las piezas de hormigón con unas medidas de $3,80 \mathrm{~m}$ por $3 \mathrm{~m}$ y un espesor de $30 \mathrm{~cm}$ apoyan sobre una primera familia de cables soportantes para luego ser postensadas a través de una segunda familia que se introduce por los conductos dispuestos en las piezas. Este mismo ingeniero, con la misma técnica, está realizando actualmente la que constituirá la primera banda tensada en Norteamérica.

Como las cubiertas colgantes, estos puentes también pueden admitir materiales de cuajado distintos al hor-

\section{LAS CUBIERTAS COLGANTES EN ESPAÑA}

La primera cubierta, de las pocas realizadas en nuestro pais, fue obra del ingeniero $\mathrm{C}$. Fernández Casado, quien, en 1958, realizó junto con los arquitectos Esquer y Belosillo el Pabellón del INI para la Feria del Campo de Madrid (Fig. 32). La cubierta con forma de tela colgada, estaba compuesta por cables de $15 \mathrm{~mm}$ situados cada $3 \mathrm{~m}$, salvando un vano de $15 \mathrm{~m}$ con $5 \mathrm{~m}$ de desnivel. Sobre éstos se dispuso una malla de redondos de $5 \mathrm{~mm}$ cada $25 \mathrm{~cm}$ y encima de ésta, a su vez, una tela metálica tipo gallinero. Como el conjunto de cables tenía una gran deformabilidad, se pensó en un principio fijar la forma con pesos auxiliares que se irian retirando a medida que se hormigonaba; pero en definitiva, seguramente acuciados por la escasez de tiempo, ya que la obra completa tuvo que ser realizada en tan sólo 60 dias, se recurrieron a equilibrios parciales, hormigonando por fajas longitudinales continuas, empleando un gran número de obreros que atacaban por

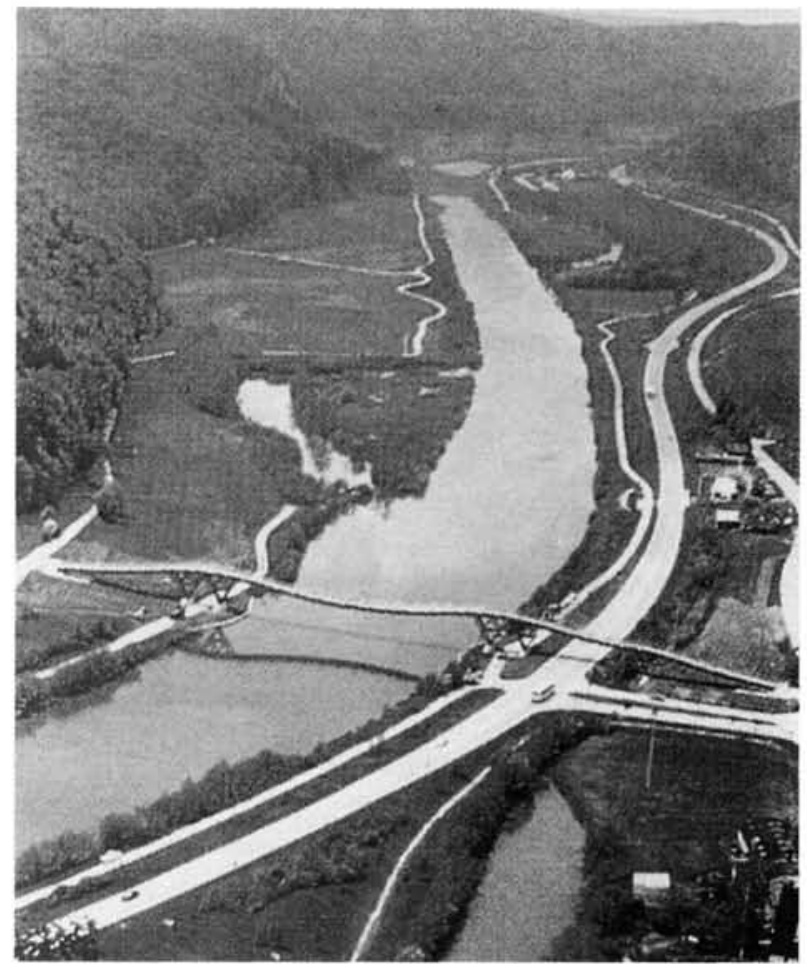

Fig. 31.-Fotografia aérea de esta sugestiva construcción realizada por J. Dietrich.

migón, como en el último ejemplo que mostramos (Figs. 30 y 31 ) realizado en madera, en la localidad bávara de Essing, por el ingeniero R. Dietrich en el año 1988.

varios tajos. La capa de hormigón de carbonilla sin finos vertida fue de $6 \mathrm{~cm}$, disponiéndose encima una tela asfáltica que actuaba como impermeabilizante.

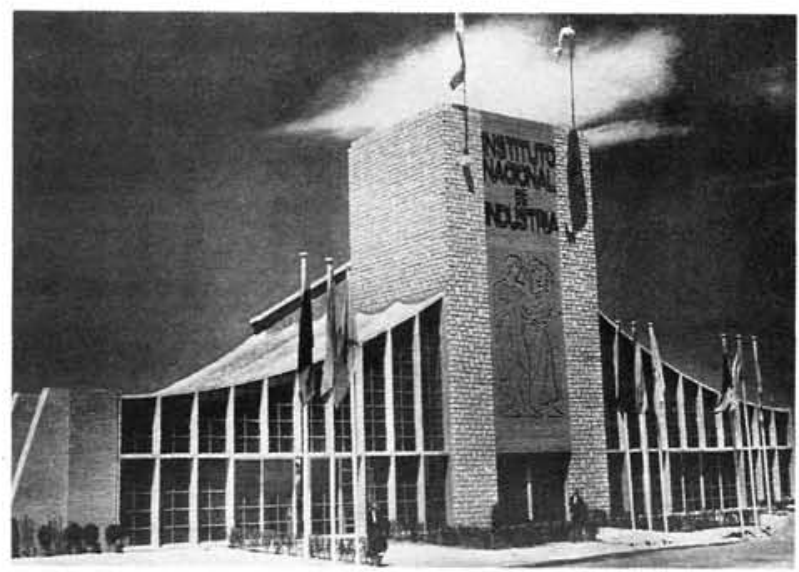

Fig. 32.-Fernández Casado. Pabellón del INI en la Feria del Campo de Madrid. Una cubierta con forma de tela colgada de $6 \mathrm{~cm}$ de espesor. http://informesdelaconstruccion.revistas.csic.es 
En 1962 A. Paez, M. Fernández Villalta y J. Cobelas realizaron una doble cubierta colgante para el salón de actos del Palacio de las Naciones de la Feria de Muestras de Barcelona (Fig. 33). Esta interesante solución, única en su género, permitió establecer una cámara de aire accesible de $1,40 \mathrm{~m}$, en la que se dispusieron las instalaciones y que además actuaba como aislamiento.
Fernández Villalta y Cobelas vuelven a plantear otra cubierta cinco años más tarde para el salón de actos de la Escuela Náutica de Portugalete, esta vez de $30 \mathrm{~m}$ de luz, utilizando un sistema de postensado que permitió, una vez fraguado el hormigón, realizar una compresión en ambos sentidos que rigidizó la estructura (Figura 34).

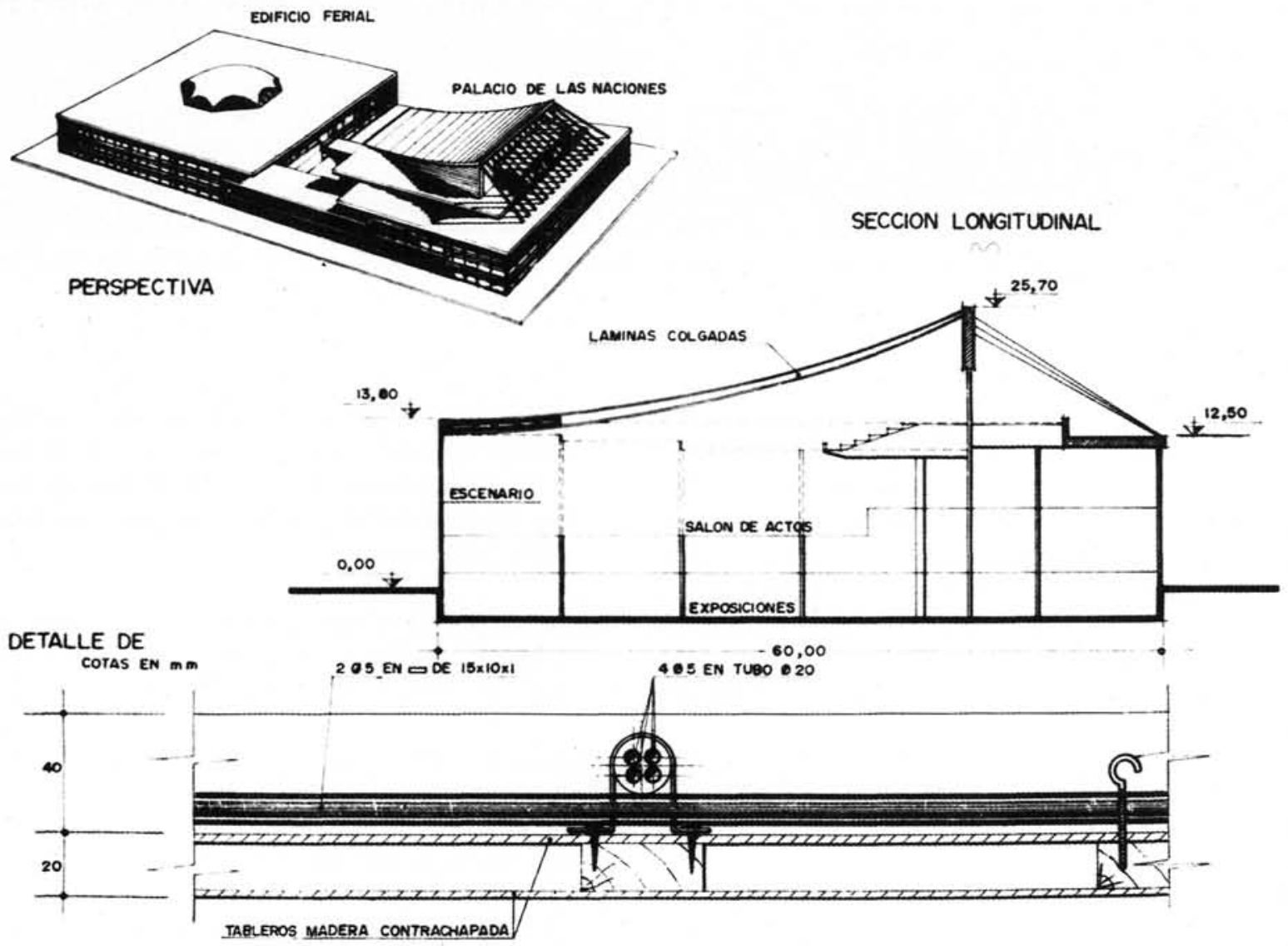

Fig. 33.-Palacio de las Naciones de la Feria de Muestras de Barcelona. Las dos cubiertas fueron postesadas en ambas direcciones.

SECCION SEGUN PARALELOS

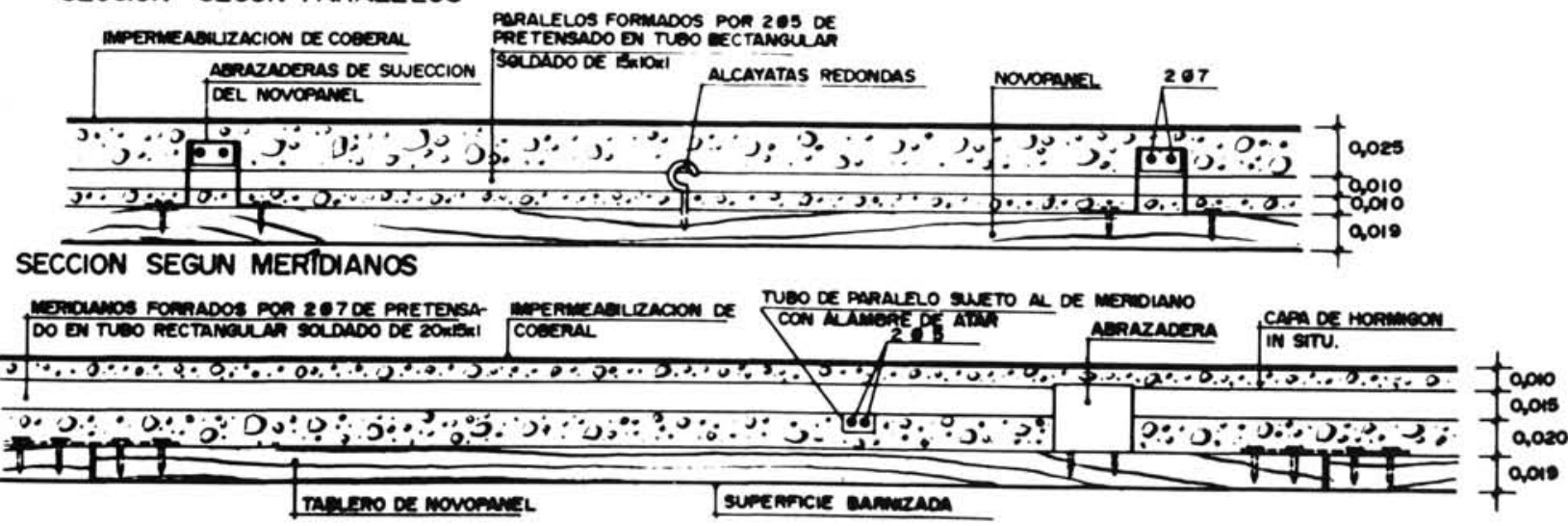

Fig. 34.-Secciones de la cubierta colgante del salón de actos de la Escuela Náutica de Portugalete. Se utilizó un encofrado perdido de madera laminada. 


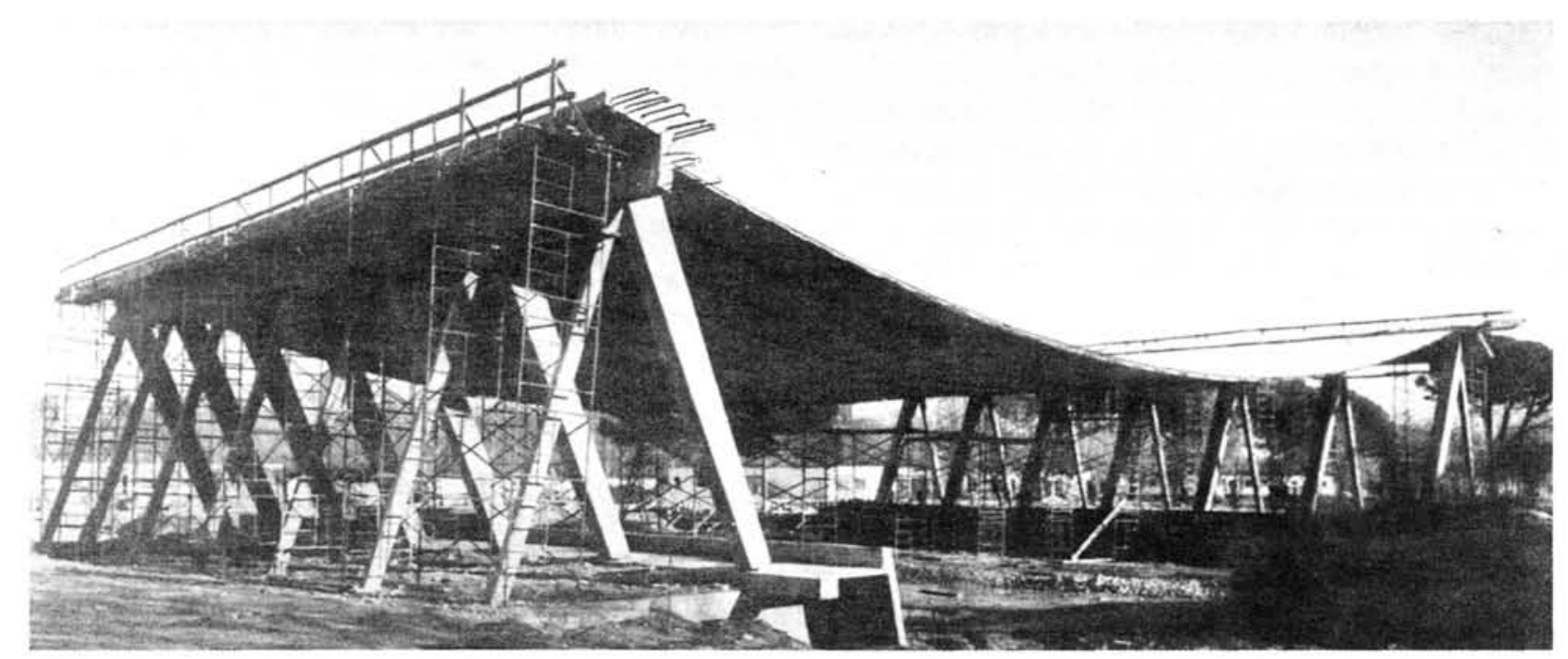

Fig. 35.-El Picadero del Club de Campo durante su construcción. Los cuchillos de sustentación están unidos por una viga de borde que arriostra la cubierta.

En 1968 vuelve a ser Fernández Casado quien diseña, para el picadero del Club de Campo de Madrid, lo que podríamos considerar un ejemplo tipo de cubierta colgante (Fig. 35). La estructura soportante estaba compuesta por pares de cables sobre los que se encajaban unas placas prefabricadas de $2,40 \mathrm{~m}$ por $1,20 \mathrm{~m}$ y $360 \mathrm{~kg}$ de peso. El pretensado se efectuó tanto en la dirección longitudinal como en la transversal, aislándose la lámina con planchas de corcho sobre las que se colocó el impermeabilizante.

\section{PRECISIONES}

(1) El historiador de la construcción Rainer Graefe ha publicado dos interesantes artículos sobre el empleo de estas estructuras en el pasado: "Hängedächer des 19. Jahrhunderts" (las cubiertas colgantes del siglo XIX) dentro del libro "Zur Geschichte des Konstruierens" Deutsche Verlags-Anstalt 1989 y "Hängedächer von 1900 bis 1950" (Cubiertas colgantes desde 1900 hasta 1950) en la revista alemana ARCUS, 1987 número 1.

(2) “Das hängende Dach", Bauwelt Verlag 1954, publicado en español con el nombre "Cubiertas colgantes" por la editorial Labor en 1958.

(3) Gottfried Böhm venia utilizando desde 1949 telas metálicas que colgaba del techo y que luego recubria de mortero, en la restauración de cielorrasos

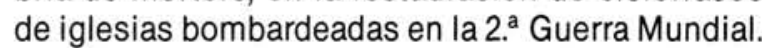

(4) Javier Manterola, "Evolución de los puentes en la historia reciente", Informes de la Construcción, abrilmayo 1984.

Nota final del autor: Este trabajo ha sido posible gracias a la colaboración del Instituto de Estructuras Superficiales Ligeras de la Universidad de Stuttgart que dirige el profesor Frei Otto. 